\title{
Sulfur-Rich Ageing Mechanism of Silicone Encapsulant Used in LED Packaging: An Experimental and Molecular Dynamic Simulation Study
}

\author{
Wei Chen ${ }^{1,2 \dagger}$, Ye Chen ${ }^{2,3 \dagger}$, Yixing Cao ${ }^{1}$, Zhen Cui ${ }^{4}$, Xuejun Fan ${ }^{5}$, Guoqi Zhang ${ }^{4}$ and \\ Jiajie Fan $^{1,2,4,6 *}$
}

${ }^{1}$ Institute of Future Lighting, Academy for Engineering and Technology, Fudan University, Shanghai, China, ${ }^{2}$ Changzhou Institute of Technology Research for Solid State Lighting, Changzhou, China, ${ }^{3}$ College of Mechanical and Electrical Engineering, Hohai University, Changzhou, China, ${ }^{4}$ Department of Microelectronics, Delft University of Technology, Delft, Netherlands, ${ }^{5}$ Department of Mechanical Engineering, Lamar University, Beaumont, TX, United States, ${ }^{6}$ Zhangjiang Technology Institute of Fudan University, Shanghai, China

\section{OPEN ACCESS}

Edited by:

Chang-Yong Nam,

Brookhaven National Laboratory (DOE), United States

Reviewed by:

Nikhil Tiwale,

Brookhaven National Laboratory

(DOE), United States

Yuchen Zhou,

Stony Brook University, United States

${ }^{*}$ Correspondence:

Jiajie Fan

jiajie_fan@fudan.edu.cn

${ }^{+}$These authors have contributed equally to this work and share first authorship

Specialty section: This article was submitted to Semiconducting Materials and

Devices,

a section of the journal

Frontiers in Materials

Received: 21 November 2021 Accepted: 19 January 2022

Published: 28 February 2022

Citation:

Chen W, Chen Y, Cao Y, Cui Z, Fan X, Zhang $G$ and Fan J (2022) Sulfur-Rich

Ageing Mechanism of Silicone Encapsulant Used in LED Packaging:

An Experimental and Molecular

Dynamic Simulation Study.

Front. Mater. 9:819294.

doi: 10.3389/fmats.2022.819294
In a light-emitting diode (LED) package, silicone encapsulant serves as a chip protector and enables the light to transmit, since it exhibits the advantages of high light transmittance, high refractive index, and high thermal stability. However, its reliability is still challenged under harsh operation conditions. In this study, the optical and mechanical properties of silicone encapsulant, including appearance, light transmittance, Young's modulus, and tensile strength, were experimentally monitored during the sulfur-rich ageing process. Meanwhile, the Fourier transform infrared (FTIR) spectroscopy and molecular dynamics (MD) simulation were used to reveal its degradation mechanism. The results show that 1 ) in the sulfur $\left(\mathrm{S}_{8}\right)$-rich ageing process, the severe vulcanization reaction occurred in silicone encapsulant assisted only by high temperature and high moisture, with the existence of $\mathrm{H}_{2} \mathrm{~S}$ as the reaction product of $\mathrm{S}_{8}$ and $\mathrm{H}_{2} \mathrm{O}$ vapor. 2) Vulcanization characterized by the formation of the sulfhydryl $(-\mathrm{SH})$ group lowered both optical and mechanical properties of silicone encapsulant. 3) The hydrolysis reaction featured by the formation of the hydroxyl $(-\mathrm{OH})$ group decreased the mechanical performances of silicone encapsulant but brought slight harm to its optical performances.

Keywords: LED packaging, silicone encapsulant, sulfur-rich, humidity, degradation mechanism, molecular dynamics

\section{INTRODUCTION}

As one of the most environmentally friendly light sources, the light-emitting diode (LED) exhibits promising performances, such as long lifetime and low power consumption (Taguchi, 2008; Watzke and Altieri-Weimar, 2015; Singh and Tan, 2018; Tan et al., 2021), and LED is popular in the lighting industry since it is highly reliable and efficient (Zhang et al., 2016; Alim et al., 2021; Bento and Cardoso, 2021; Bispo-Jr et al., 2021). Silicones are polymeric substances consisting of repeating units of siloxane (alternating silicon and oxygen chains) and organic side groups, showing a high refractive index and high optical transparency (Lin et al., 2010; Kim et al., 2013; Tong et al., 2018; Kim et al., 2019). Therefore, they are widely used as one of the encapsulant materials in LED packaging with the functions of light-extraction and chip-protection. However, their optical and mechanical properties 
are often affected by harsh environmental conditions containing moisture, temperature, pollutions, and contaminants, such as sulfur (Lee et al., 2015; Luo et al., 2016; Khalilullah et al., 2017; Made et al., 2017).

Some previous researchers have revealed that the stability of silicone encapsulant materials determines the performance and lifetime of LEDs. For instance, Zhang (2015) used the finite element method to quantitatively evaluate the degradation of organosilicon and developed a lumen depreciation model, which could help LED manufacturers to avoid time-consuming reliability tests. Chang et al. (2016) studied the drying and wetting air ageing processes involving silicone materials, and the results revealed that high humidity and temperature will exacerbate the degradation of silicone, which was explained by chemical decomposition of cross-linker units that connect polysiloxane backbones and methyl groups attached to silicon atoms. Wu et al. (2017a) analyzed the thermal oxidation degradation mechanism of silicone by using the X-ray photoelectron spectroscopy (XPS) and nuclear magnetic resonance (NMR) techniques. The results revealed that the hardness and compression set of silicone increases with ageing time. The increases in the surface roughness and ageing time all potentially resulted in the deteriorated sealing performance. Luo et al., (2017), Fan et al., (2019) studied a long-term degradation mechanism of phosphor/silicone composites under the conditions of high temperature and humidity with comparing the optical and mechanical properties of the aged composites. Khalilullah et al. (2017), Hoque et al. (2019) investigated the influence of humidity on phosphor/silicone composites and reported the reversibility of the hygroscopic expansion process occurring in the absorption/desorption cycle. They also concluded that exposure to moisture will cause permanent damage to silicone materials. Huang et al. (2015a) presented the failure mechanism of mid-power whitelight LEDs aged under saturated moisture conditions as the silicone was carbonized during the ageing process. They summarized that the phosphor's self-heating and the excessive absorption of blue light contribute to a significant rise in the internal temperature, resulting in silicone carbonization (Huang et al., 2015b). Cai et al. (2020) studied the effect of silicone encapsulation degradation on the LED lumen decay and color shift, and they found the yellowing failure of silicone is concluded as the oxidation and hydrolysis of silicone materials.

The LED was attacked by the sulfur and sulfide coming from the air atmosphere, when working in harsh environments such as mine, chemical fertilizer plant, livestock farm, and sewage treatment plant. Silicone is prone to absorb sulfur and sulfide causing the degradation of itself (Wang et al., 2019). For example, Zibold et al. (2017) studied the impacts of hydrogen sulfide on light output power of LEDs. Different decreases were measured in different LED packages, after $380 \mathrm{~h}$ of ageing with $10 \mathrm{ppm}$ hydrogen sulfide. Wu et al. (2017b) conducted the roomtemperature-vulcanization (RTV) process on silicone under varying temperatures and humidity. The results revealed that the humidity and temperature in the vulcanization environment highly influence the hydrophobicity transfer ability, functional groups, and thermal stability of silicone. Besides, if the sulfur penetrates the packaging, silver-plated copper in the LED lead frame is susceptible to corrosion featured with forming $\mathrm{Ag}_{2} \mathrm{~S}$, which will reduce the light extraction efficiency (ChenlanXu et al., 2018).

According to the aforementioned literature review, there are numerous studies on the degradation mechanism of silicone under the conditions of high temperature and humidity; however, reports on the sulfur-rich ageing mechanism of LED silicone encapsulant are rare. Thus, in this study, we conducted the high temperature, high humidity, and sulfur-rich ageing experiments on the LED silicone encapsulant samples. Their optical and mechanical properties were measured during ageing, and the inherent degradation mechanisms were investigated by using both experiments and molecular dynamic (MD) simulation. The remaining parts of this article are organized as follows: Sample Preparation, Experiment, and Simulation Methods section introduces the methods of sample preparation, experiment setup, and simulation process; Results and Discussion section analyzes the ageing mechanism based on both experimental and simulation results; Conclusion section presents the concluding remarks.

\section{SAMPLE PREPARATION, EXPERIMENT, AND SIMULATION METHODS}

In this section, the preparation process of test samples is introduced first. Then, the four different ageing tests are designed. The simulation procedure based on molecular dynamics $(\mathrm{MD})$ is given at last.

\section{Sample Preparation}

The preparation procedure of the test sample is shown in Figure 1: first, the precursors KJC-1200A and KJC-1200B purchased from Shin-Etsu Chemical Co. Ltd. were mixed in the mass ratio of $1: 1$ and manually stirred for $10 \mathrm{~min}$. Next, the mixture was placed in a vacuum bucket to remove foam. Subsequently, the foamless mixture that was poured into a polytetrafluoroethylene (PTFE) tube was cured in a temperature chamber operated at $140^{\circ} \mathrm{C}$ for $3 \mathrm{~h}$. After cooling, the cured silicone film with the size of $50^{\star} 50^{\star} 1 \mathrm{~mm}$ was prepared. Finally, the cured silicone film was cut into a rectangle-shaped sample with the size of $40^{\star} 5^{\star} 1 \mathrm{~mm}$ and disc-shaped sample with the size of $\Phi 23^{\star} 1 \mathrm{~mm}$, used for mechanical properties measurement and optical properties measurement, respectively.

\section{Ageing Experiments}

To evaluate the influence of sulfur and humidity on the degradation of silicone, this article presented four different accelerated ageing conditions: 1) $100^{\circ} \mathrm{C}$ ageing; 2) $100^{\circ} \mathrm{C}+$ $100 \% \mathrm{RH}$ ageing; 3) $100^{\circ} \mathrm{C}+$ Sulfur ageing; and 4) $100^{\circ} \mathrm{C}+$ $100 \% \mathrm{RH}+$ Sulfur ageing. To accelerate the degradation, a high temperature of $100^{\circ} \mathrm{C}$ was applied in all four conditions. The conditions $100^{\circ} \mathrm{C}$ ageing and $100^{\circ} \mathrm{C}+$ Sulfur ageing were carried out in the setup shown in Figure 2A. The test samples placed on the glass reactor were heated in the temperature chamber with a temperature of $100^{\circ} \mathrm{C}$. In $100^{\circ} \mathrm{C}+$ Sulfur 

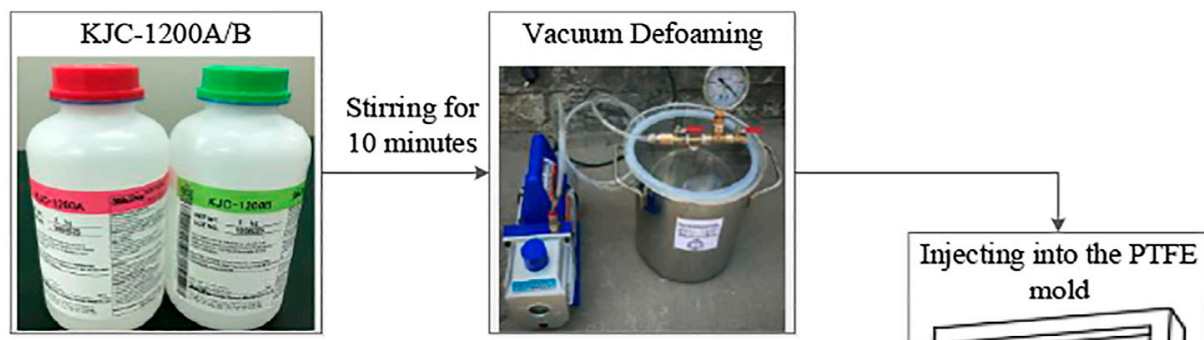

Injecting into the PTFE
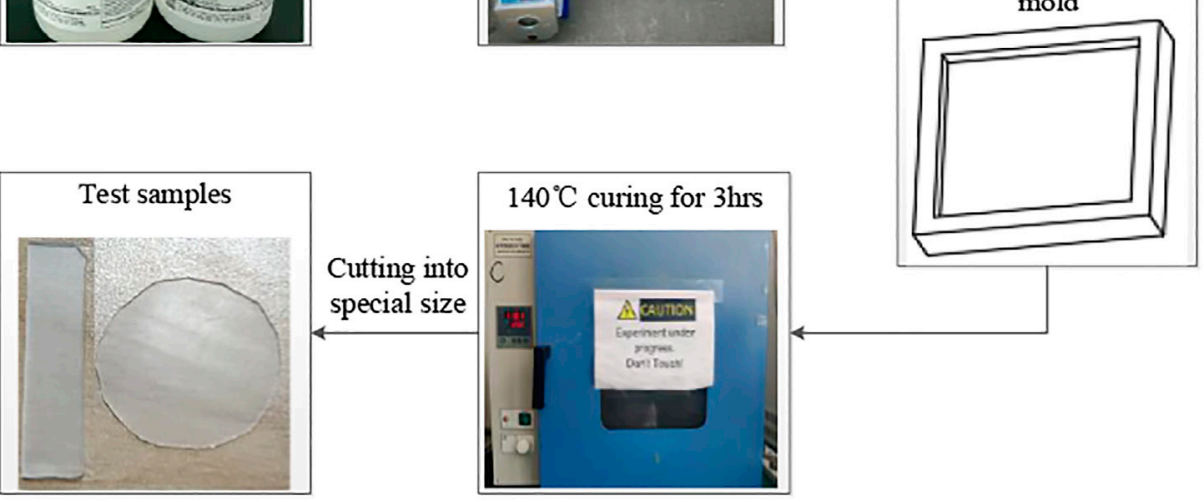

FIGURE 1 | Test samples preparation procedure.

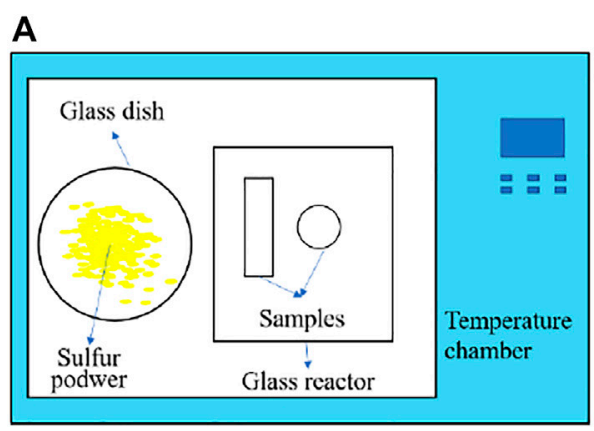

B

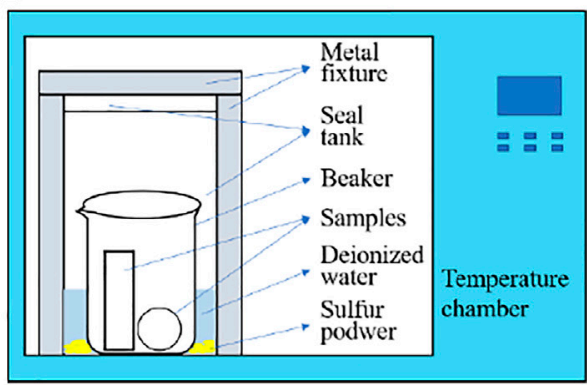

FIGURE 2 | Accelerated ageing test setups: (A) $100^{\circ} \mathrm{C}+$ Sulfur; and (B) $100^{\circ} \mathrm{C}+100 \% R H+$ Sulfur.

ageing, $10 \mathrm{~g}$ chemically pure sulfur $\left(\mathrm{S}_{8}\right)$ placed on the glass dish was put into the thermal chamber. As shown in Figure 2B, a 300ml PTFE seal tank with $30 \mathrm{ml}$ deionized water was used to guarantee the saturated wet condition. Compared to $100^{\circ} \mathrm{C}+$ $100 \% \mathrm{RH}$ ageing, $10 \mathrm{~g}$ chemically pure sulfur $\left(\mathrm{S}_{8}\right)$ was added in the deionized water in $100^{\circ} \mathrm{C}+100 \% \mathrm{RH}+$ Sulfur ageing.

All test samples were subjected to a constant temperature chamber with a $1008 \mathrm{~h}$ ageing process. Each group consisted of 35 rectangleshaped samples and five disc-shaped samples. A total of five rectangle-shaped and five disc-shaped samples were taken out for the property measurement every $168 \mathrm{~h}$. The mechanical properties of the rectangle-shaped samples, including Young's modulus and tensile strength, were measured under the tensile test machine (ZQ-980A, Zhiqu). The light transmittances of the disc-shaped samples were measured using the spectrophotometer (CM-3700A, Konica), and their functional groups were identified using the FTIR spectrometer (iS50, Nicolet).

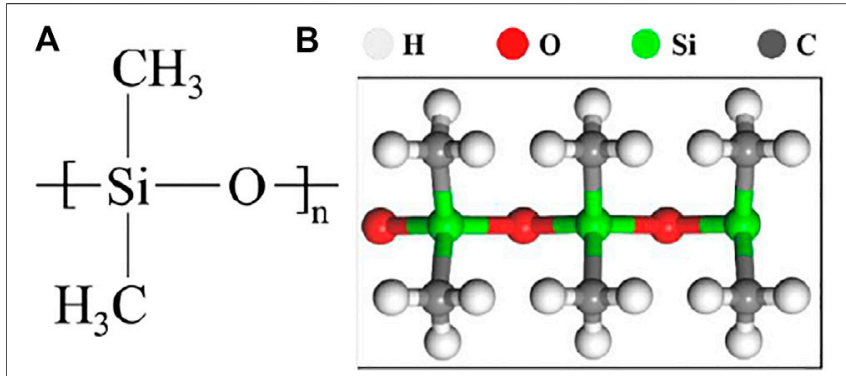

FIGURE 3 | (A) Chemical formula and (B) molecular structure of silicone.

\section{Simulation Setup}

To understand the adsorbing mechanism of $\mathrm{H}_{2} \mathrm{O}$ and $\mathrm{H}_{2} \mathrm{~S}$ on the silicone (polydimethylsiloxane, PDMS) molecules, as shown in Figure 3, the quantum mechanical calculation based on the 
TABLE 1 | Appearance observed in test samples subjected to four different ageing conditions.

\begin{tabular}{|c|c|c|c|c|c|c|c|}
\hline \multirow[t]{2}{*}{ Group } & \multicolumn{7}{|c|}{ Time (h) } \\
\hline & $\mathbf{O h}$ & $168 \mathrm{~h}$ & $336 \mathrm{~h}$ & $504 \mathrm{~h}$ & $672 \mathrm{~h}$ & $840 h$ & $1,008 h$ \\
\hline $100^{\circ} \mathrm{C}$ ageing & & & & & & & \\
\hline $100^{\circ} \mathrm{C}+100 \% \mathrm{RH}$ ageing & & & & & & & \\
\hline $100^{\circ} \mathrm{C}+$ Sulfur ageing & & & & & & & \\
\hline $100^{\circ} \mathrm{C}+100 \% R H+$ Sulfur ageing & & & & & 5 & & \\
\hline
\end{tabular}
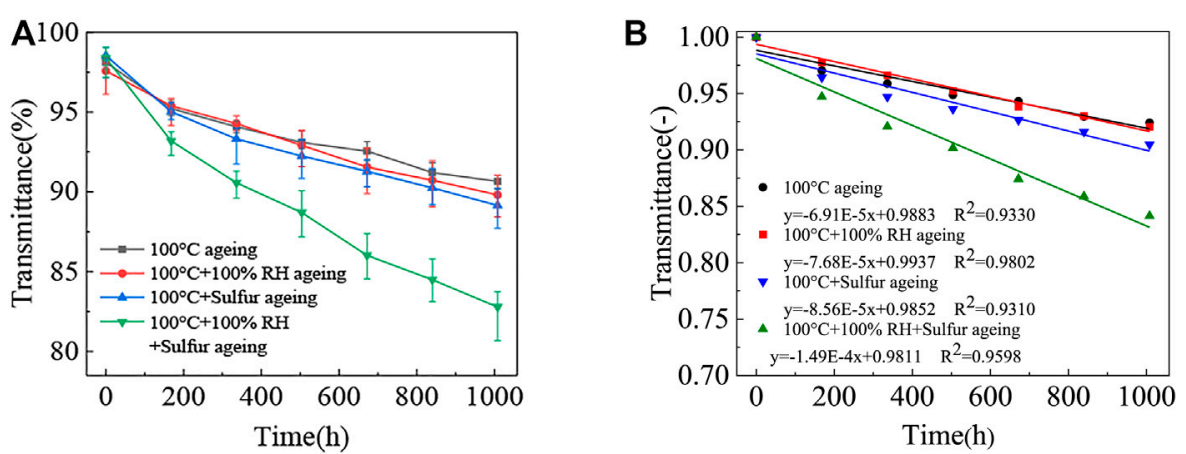

FIGURE 4 | (A) Light transmittance of four groups of samples vs. ageing time; and (B) their linear fitting results.

density functional theory (DFT) was conducted in $\mathrm{DMol}^{3}$ and CASTEP. The energies originated from electronic interaction were dealt with in using the generalized gradient approximation (GGA) with the Perdew-Burke-Ernzerhof (PBE) method (Fan et al., 2020). Double numerical basis sets with polarization functions (DNPs) with the basis file 3.5 were selected in this study. The Grimme custom method for DFT-D was used to dispose weak interactions between PDMS and $\mathrm{H}_{2} \mathrm{O}$ or $\mathrm{H}_{2} \mathrm{~S}$. The convergence tolerances of geometry optimization were set at: energy $=1.0 \mathrm{e}-5 \mathrm{Ha}$, $\max$, force $=0.002 \mathrm{Ha} / \AA$, max, and displacement $=0.005 \AA$. The adsorption distances between PDMS and $\mathrm{H}_{2} \mathrm{O}$ or $\mathrm{H}_{2} \mathrm{~S}$ were $3 \AA$.

\section{RESULTS AND DISCUSSION}

In this section, the optical and mechanical properties of prepared test samples undergoing different ageing processes are discussed, and the degradation mechanisms are revealed by using the FTIR and MD simulation.

\section{Optical Properties}

The data presented in Table 1 reveal that the appearance of the silicone samples changes when the samples were aged. It shows that the $1008 \mathrm{~h}$-long-term ageing increased the degree of yellowing of test samples. The $100^{\circ} \mathrm{C}$ ageing and $100^{\circ} \mathrm{C}+100 \% \mathrm{RH}$ ageing groups showed the similar phenomenon that no evident appearance of color changes was observed at the end of the ageing. However, in the $100^{\circ} \mathrm{C}$ + Sulfur ageing and $100^{\circ} \mathrm{C}+100 \% \mathrm{RH}+$ Sulfur ageing, the appearance of the color of samples changed to deep yellow after ageing, more severe in $100^{\circ} \mathrm{C}+100 \% \mathrm{RH}+$ Sulfur ageing, which indicates that both sulfur and moisture exerted an acceleration impact on the yellowing of silicone samples.

The light transmittance is one of the key indicators for silicone encapsulant, since the light extraction efficiency of LED 


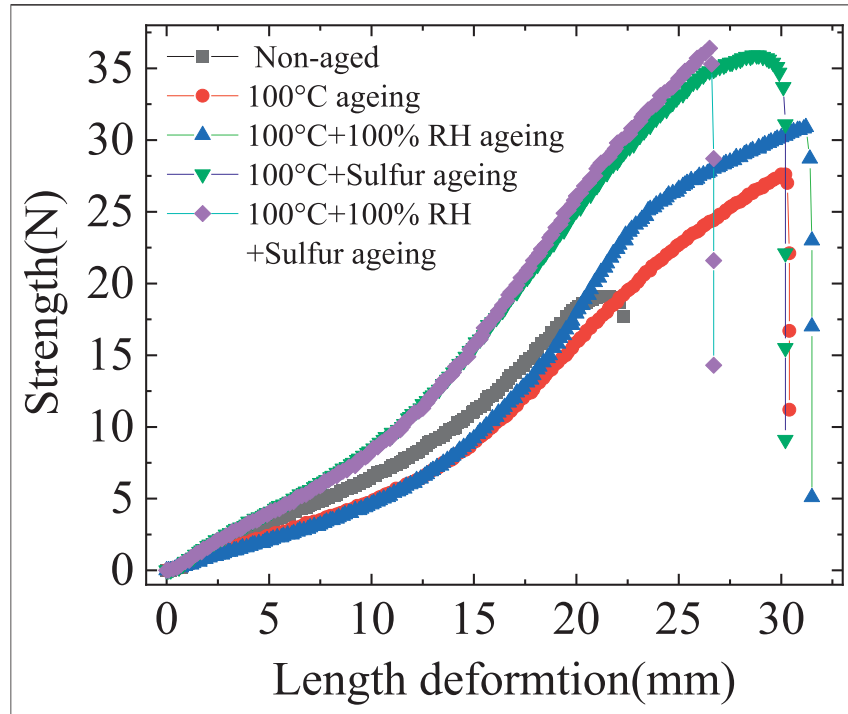

FIGURE 5 | Tensile test curves of samples.

packaging is highly affected by the light transmittance (Pan et al., 2021; Wang et al., 2014). Furthermore, the light transmittance degradation path of the four groups of samples and their linear fitting results are demonstrated in Figure 4. The transmittance data in Figure 4 are an average value of transmittances measured in the visible spectrum range, and the measurement step is $10 \mathrm{~nm}$. The degradation rate in light transmittance is indicated by the slope of linear fitting, and the order of slopes under four different ageing conditions was that: $100^{\circ} \mathrm{C}$ ageing: $-6.91 \mathrm{e}-5>100^{\circ} \mathrm{C}+$ 100\%RH ageing: $-7.68 \mathrm{e}-5>100^{\circ} \mathrm{C}+$ Sulfur ageing: $-8.56 \mathrm{e}-5>$ $100^{\circ} \mathrm{C}+100 \% \mathrm{RH}+$ Sulfur ageing: $-1.49 \mathrm{e}-4$. The $100^{\circ} \mathrm{C}$ ageing and $100^{\circ} \mathrm{C}+100 \% \mathrm{RH}$ ageing groups showed the similar degradation rate in light transmittance, and a slight increment can be observed in $100^{\circ} \mathrm{C}+$ Sulfur ageing. The reason is that vaporized sulfur in $100^{\circ} \mathrm{C}+$ Sulfur ageing was deposited and permeated to the surface of silicone, but no chemical reaction occurred, resulting in obvious appearance of color change and slight light transmittance change. However, the degradation rate of light transmittance in $100^{\circ} \mathrm{C}+100 \% \mathrm{RH}+$ Sulfur ageing was the largest compared to that of other conditions. According to Wang et al., (2019) and Manconi and Lens, (2009), the sulfur $\left(S_{8}\right)$ can be transformed into hydrogen sulfide $\left(\mathrm{H}_{2} \mathrm{~S}\right)$ with existence of water vapor, and the strong sensitivity of silicone toward $\mathrm{H}_{2} \mathrm{~S}$ was confirmed. Therefore, the chemical reaction between silicone and $\mathrm{H}_{2} \mathrm{~S}$ might lead to the most serious optical property deterioration of test samples in $100^{\circ} \mathrm{C}+100 \% \mathrm{RH}+$ Sulfur ageing.

\section{Mechanical Properties}

The typical tensile test curves of samples before and after ageing are plotted in Figure 5. Tensile strength $(\sigma)$ and Young's modulus (E) can be calculated using tensile test data by following Eqs 1, 2:

$$
\begin{aligned}
\sigma & =\frac{F_{\text {max }}}{A} \\
E & =\frac{\sigma}{d L / L}
\end{aligned}
$$

in which $F_{\text {max }}, A, L$, and $d L$ are maximum strength at sample breaking, cross-section area of the sample, length of the sample, and length deformation at sample breaking, respectively. In this study, the values of $A$ and $L$ are $5 \mathrm{~mm}^{2}$ and $40 \mathrm{~mm}$, respectively.

Figure 6 shows the mechanical properties of the silicone samples subjected to four different ageing conditions. The increases in Young's modulus and tensile strength had occurred in the four groups of silicone samples. The Young's modulus and tensile strength of silicone under humidity stress ageing conditions were higher than those of the samples aged under dry conditions because the hydrolysis reaction occurred under high humidity conditions (Fan et al., 2019; Hoque et al., 2019). In addition, the Young's modulus and tensile strength of the silicone samples treated under the sulfurized environment were largely higher than those of the samples aged without sulfur, which indicated that sulfur could accelerate the mechanical degradation of silicone. As the most severe mechanical degradation of the silicone samples was occurred in the $100^{\circ} \mathrm{C}$
A

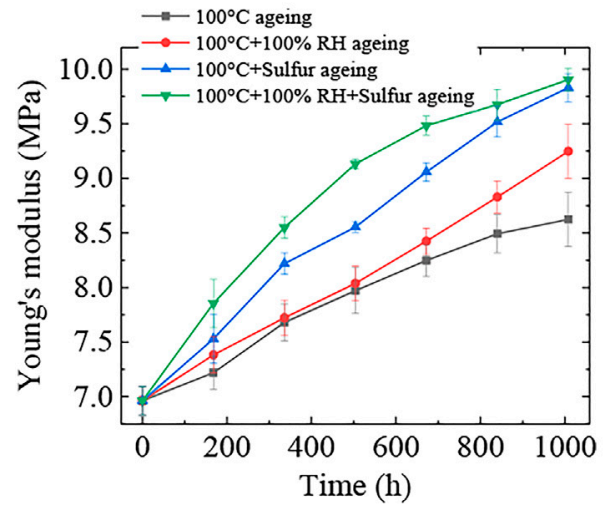

B

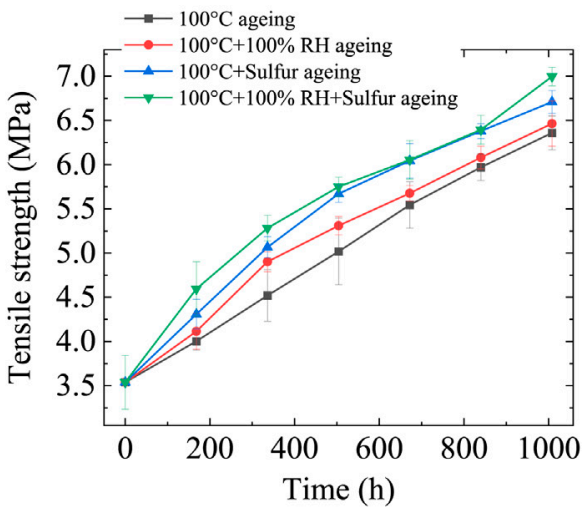

FIGURE 6 | Mechanical properties of four groups of samples vs. ageing time: (A) Young's modulus; and (B) tensile strength. 

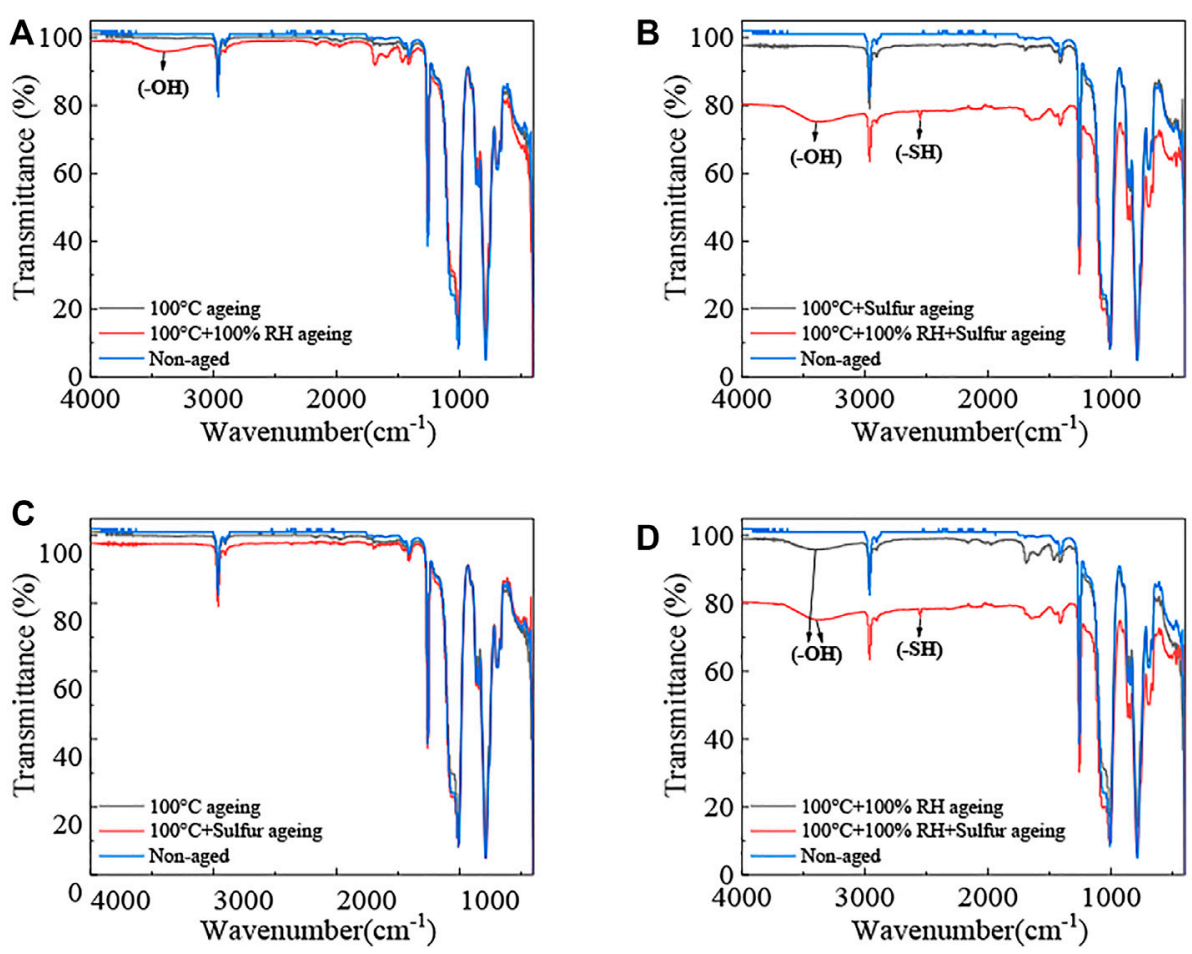

FIGURE 7 | FTIR spectra of silicone samples: (A) effect of humidity in high temperature; (B) effect of humidity in sulfur vapor; (C) effect of sulfur in dry air; and (D) effect of sulfur in water vapor.

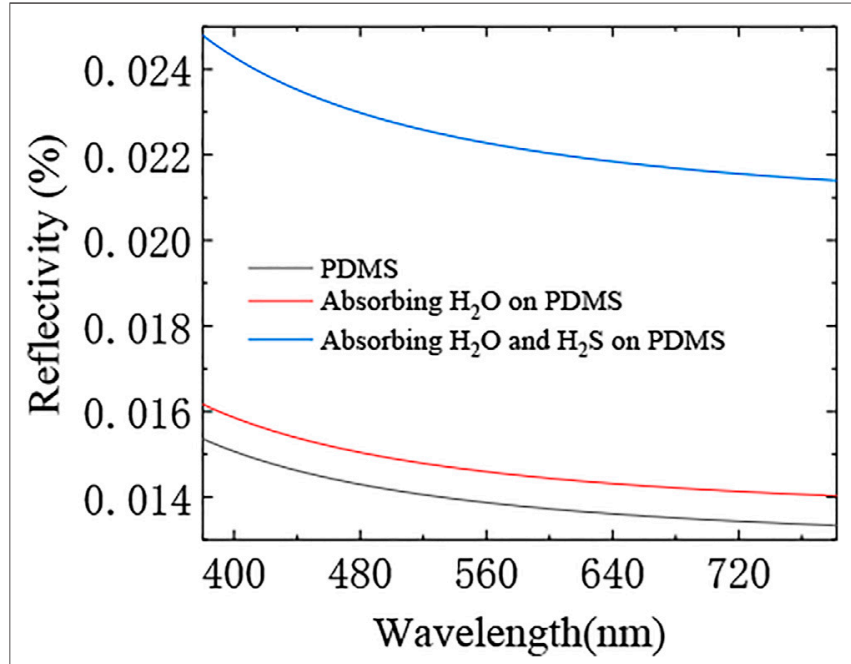

FIGURE 8 | Simulated reflectivity of silicone (PDMS) with adsorption of different molecules.

$+100 \% \mathrm{RH}+$ Sulfur ageing group, it was speculated that besides the hydrolysis reaction, the samples also reacted with $\mathrm{H}_{2} \mathrm{~S}$.

\section{Degradation Mechanism Analysis}

To explain the aforementioned optical and mechanical degradation of the silicone samples, FTIR and MD simulation techniques were used to analyze their degradation mechanisms under different ageing conditions.

Figure 7 shows and compares the FTIR spectra recorded for silicone samples subjected to four different ageing environments. Compared to unaged test samples, the absorption peak intensities of the aged samples around $787 \mathrm{~cm}^{-1}$ (C-H rolling vibration), $1,260 \mathrm{~cm}^{-1} \quad$ (C-H stretching vibration), 2,960 $\mathrm{cm}^{-1} \quad(\mathrm{C}-\mathrm{H}$ stretching vibration), and $1,080 \mathrm{~cm}^{-1} \quad(\mathrm{Si}-\mathrm{O}-\mathrm{Si}$ stretching vibration) dropped by varying degrees, indicating various degrees of degradation in the main and side chains of silicone samples ( $\mathrm{Wu}$ et al., 2017a). Hydrolysis and vulcanization reactions are represented by the hydroxyl group $(-\mathrm{OH})$ with FTIR absorption peaks around $3,400 \mathrm{~cm}^{-1}$ (Salehpour and Dube, 2012) and sulfhydryl group (-SH) with FTIR absorption peaks around $2,570 \mathrm{~cm}^{-1}$ (Fei et al., 2017). As shown in Figure 7, the hydrolysis reaction happened in both $100^{\circ} \mathrm{C}+$ $100 \% \mathrm{RH}$ ageing and $100^{\circ} \mathrm{C}+100 \% \mathrm{RH}+$ Sulfur ageing; however, vulcanization reactions only appeared in $100^{\circ} \mathrm{C}+100 \% \mathrm{RH}+$ Sulfur ageing. Meanwhile, the new absorption peaks between 1,550 and $1,800 \mathrm{~cm}^{-1}$ were attributed to the reaction of sulfur and small amounts of impurities in silicone such as unsaturated vinyl group $-\mathrm{CH}=\mathrm{CH}_{2}$ (Nazi et al., 2012). No extra absorption peak was observed in $100^{\circ} \mathrm{C}$ ageing and $100^{\circ} \mathrm{C}+$ Sulfur ageing, indicating that no new group formed after ageing. Generally speaking, high temperature damaged the skeletal structure of silicone; the hydrolysis reaction occurred with presence of moisture; sulfur did not directly react with silicone; the vulcanization reaction occurred with the existence of $\mathrm{H}_{2} \mathrm{~S}$ as the reaction product of sulfur and water vapor. 

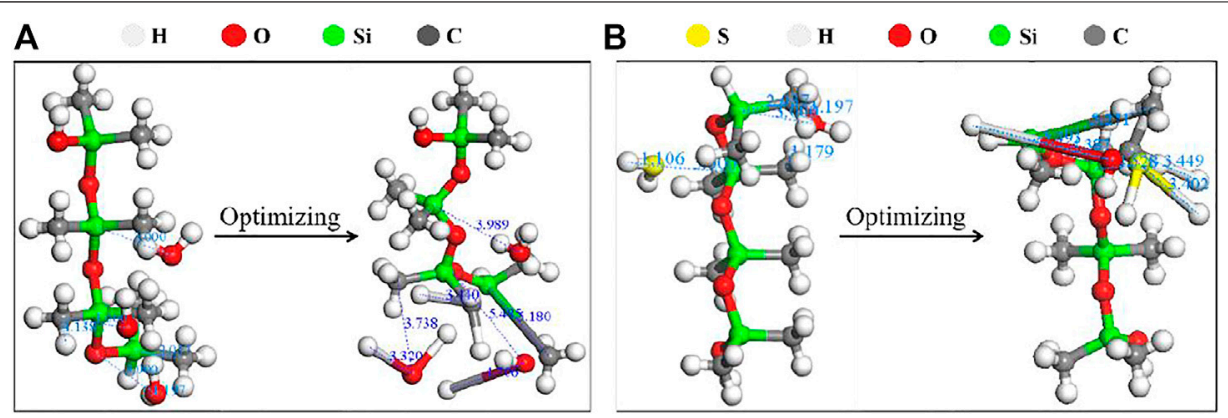

FIGURE 9 | Simulated geometric optimization results: (A) adsorption of $\mathrm{H}_{2} \mathrm{O}$ on PDMS; and (B) adsorption of $\mathrm{H}_{2} \mathrm{O}$ and $\mathrm{H}_{2} \mathrm{~S}$ on PDMS.

To reveal the reactions under ageing, molecular simulations between PDMS and $\mathrm{H}_{2} \mathrm{O}$ or $\mathrm{H}_{2} \mathrm{~S}$ were conducted in $\mathrm{DMol}^{3}$ and CASTEP. The simulated reflectivity and geometric optimization results are shown in Figures 8, 9, respectively. The reflectivity of silicone slightly increased when $\mathrm{H}_{2} \mathrm{O}$ was adsorbed on the PDMS molecules, while a marked increase in reflectivity was observed when both $\mathrm{H}_{2} \mathrm{O}$ and $\mathrm{H}_{2} \mathrm{~S}$ were adsorbed on the PDMS molecules. Light transmittance of silicone is inversely proportional to the reflectivity, so the simulated reflectivity results are consistent with experimental light transmittances of any aged samples subjected to $100^{\circ} \mathrm{C}+100 \%$ $\mathrm{RH}$ ageing and $100^{\circ} \mathrm{C}+100 \% \mathrm{RH}+$ Sulfur ageing as shown in Figure 4. The adsorption of $\mathrm{H}_{2} \mathrm{O}$ on PDMS resulted in the elongation of the $\mathrm{Si}-\mathrm{C}$ bond in $\mathrm{Si}-\mathrm{CH}_{3}$ and the $\mathrm{H}-\mathrm{OH}$ bond in $\mathrm{H}_{2} \mathrm{O}$, generating the $-\mathrm{Si}-\mathrm{OH}$ group. The adsorption of $\mathrm{H}_{2} \mathrm{O}$ and $\mathrm{H}_{2} \mathrm{~S}$ on PDMS led to the elongation of the $\mathrm{Si}-\mathrm{C}$ bond in $\mathrm{Si}-\mathrm{CH}_{3}$, the $\mathrm{C}-\mathrm{H}$ bond in $-\mathrm{CH}_{3}$, the $\mathrm{H}-\mathrm{OH}$ bond in $\mathrm{H}_{2} \mathrm{O}$, and the $\mathrm{H}-\mathrm{SH}$ bond in $\mathrm{H}_{2} \mathrm{~S}$, generating the $-\mathrm{Si}-\mathrm{OH}$ and $-\mathrm{CH}_{2} \mathrm{SH}$ groups. Finally, hydrolysis and vulcanization reactions are assumed as shown in Eqs 3, 4.

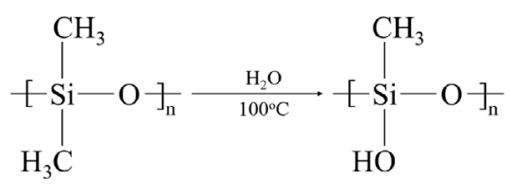

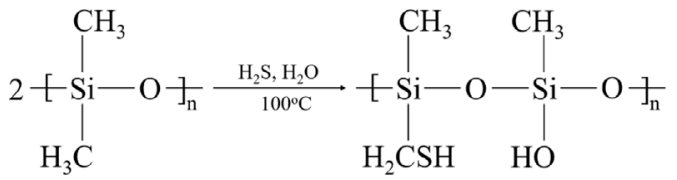

\section{CONCLUSION}

In this study, the optical and mechanical degradations of LED silicone encapsulant aged under the sulfur-rich and high humidity conditions were studied with both experiments and molecular dynamics (MD) simulation. The results reveal that 1) a significant deterioration in the optical and mechanical performances of silicone encapsulant was observed in the ageing condition of sulfur-rich and high humidity environments, attributing to the formation of $\mathrm{H}_{2} \mathrm{~S}$ as the reaction product of sulfur and water vapor; 2) both hydrolysis and vulcanization reactions took adverse effects on mechanical properties of silicone, but optical properties deterioration was more sensitive to vulcanization reactions; 3) hydrolysis and vulcanization were characterized by the formation of the hydroxyl (-OH) group and sulfhydryl $(-\mathrm{SH})$ group, respectively, and their reaction equations were derived by FTIR results and verified by MD simulation. These results obtained in this study can help in the selection of silicone encapsulant materials used in high-power LED packaging and give solutions to improve the reliability of the LED packaging.

\section{DATA AVAILABILITY STATEMENT}

The raw data supporting the conclusion of this article will be made available by the authors, without undue reservation.

\section{AUTHOR CONTRIBUTIONS}

WC: writing-original draft preparation. YeC: experiments, data collection, and analysis. YiC: simulation and analysis. ZC: technical support on simulation. XF: supervision. GZ: supervision. JF: conceptualization, methodology, writing-review and editing, project administration, funding acquisition, and supervision.

\section{FUNDING}

The work described in this article was partially supported by the National Natural Science Foundation of China (51805147), Shanghai Science and Technology Development Foundation (21DZ2205200), Shanghai Pujiang Program (2021PJD002), and Changzhou Sci\&Tech Program (CJC20209003). 


\section{REFERENCES}

Alim, M. A., Abdullah, M. Z., Aziz, M. S. A., and Kamarudin, R. (2021). Die Attachment, Wire Bonding, and Encapsulation Process in LED Packaging: A Review. Sensors Actuators A: Phys. 329, 112817. doi:10.1016/j.sna.2021. 112817

Bento, F., and Cardoso, A. J. M. (2021). Comprehensive Survey and Critical Evaluation of the Performance of State-Of-The-Art LED Drivers for Lighting Systems. Chin. J. Electr. Eng. 7 (2), 21-36. doi:10.23919/cjee.2021.000013

Bispo-Jr, A. G., Jr, Saraiva, L. F., Lima, S. A. M., Pires, A. M., and Davolos, M. R. (2021). Recent Prospects on Phosphor-Converted LEDs for Lighting, Displays, Phototherapy, and Indoor Farming. J. Lumin. 237, 118167. doi:10.1016/j. jlumin.2021.118167

Cai, M., Liang, Z., Qin, Y., Fan, J., Ma, D., Yang, D., et al. (2020). Effects of Silicone Lens Aging on Degradation Kinetics of Light-Emitting Diode Package in Various Accelerated Testing. Opt. Mater. 107, 110071. doi:10.1016/j.optmat. 2020.110071

Chang, H., Wan, Z., Chen, X., Wan, J., Luo, L., Zhang, H., et al. (2016). Temperature and Humidity Effect on Aging of Silicone Rubbers as Sealing Materials for Proton Exchange Membrane Fuel Cell Applications. Appl. Therm. Eng. 104, 472-478. doi:10.1016/j.applthermaleng.2016.05.095

Chen, L., Xu, H. X., Zhao, H., and Zhao, Z. B. (2018). “The Failure Analysis of LED Sulfur Corrosion," in Presented at the 2018 19th International Conference on Electronic Packaging Technology (ICEPT), 1064-1069. doi:10.1109/icept.2018. 8480820

Fan, J., Wang, Z., Deng, Z., Fan, X., Zhang, G., and Zhang, G. (2019). High Moisture Accelerated Mechanical Behavior Degradation of Phosphor/Silicone Composites Used in White Light-Emitting Diodes. Polymers (Basel) 11 (8), 1-16. doi:10.3390/polym11081277

Fan, J., Zhou, L., Cui, Z., Chen, S., Fan, X., and Zhang, G. (2020). Hydrolysis Kinetic Study of CaAlSiN3:Eu2+ Red Phosphor with Both Water Immersion Test and First-Principles Calculation. J. Lumin. 219, 116874. doi:10.1016/j.jlumin.2019. 116874

Fei, Y., Liu, C., Li, F., Chen, M., Tong, H., Liu, C., et al. (2017). Combined Modification of clay with Sulfhydryl and Iron: Toxicity Alleviation in CrContaminated Soils for Mustard (Brassica Juncea) Growth. J. Geochemical Exploration 176, 2-8. doi:10.1016/j.gexplo.2016.10.014

Hoque, M. A., Bradley, R. K., Fan, J., and Fan, X. (2019). Effects of Humidity and Phosphor on Silicone/phosphor Composite in white Light-Emitting Diode Package. J. Mater. Sci. Mater. Electron. 30 (23), 20471-20478. doi:10.1007/ s10854-019-02393-8

Huang, J., Golubovic, D. S., Koh, S., Yang, D., Li, X., Fan, X. J., et al. (2015). Degradation Mechanisms of Mid-power White-Light LEDs under HighTemperature-Humidity Conditions. IEEE Trans. Device Mater. Relib. 15 (2), 220-228. doi:10.1109/tdmr.2015.2418345

Huang, J., Golubovic, D. S., Koh, S., Yang, D., Li, X., Fan, X., et al. (2015). Rapid Degradation of Mid-power White-Light LEDs in Saturated Moisture Conditions. IEEE Trans. Device Mater. Relib. 15 (4), 478-485. doi:10.1109/ tdmr.2015.2468587

Khalilullah, I., Rezaa, T., Chena, L., Placetteb, M., Monayem H., A. K. M., Jiang, M., et al. (2017). "In-situ Characterization of Moisture Absorption and Hygroscopic Swelling of Silicone/phosphor Composite Film and Epoxy Mold Compound in LED Packaging," in 2017 18th International Conference on Thermal, Mechanical and Multi-Physics Simulation and Experiments in Microelectronics and Microsystems (EuroSimE), 1-9. doi:10. 1109/eurosime.2017.7926275

Kim, H. Y., Lee, J. W., Moon, Y. M., Oh, J. T., Jeong, H. H., Song, J. O., et al. (2019). Improvement in the Reliability of AlGaInP-Based Light-Emitting Diode Package Using Optimal Silicone and Leadframe Structure, (in English). ECS J. Solid State. Sci. Technol. 9 (1), 015014. doi:10.1149/2. 0332001jss

Kim, S.-M., Baek, J. H., Hwang, N., Kim, Y.-S., Wi, S.-K., Um, S. H., et al. (2013). Efficiency Enhancement of White Light-Emitting Diodes via Nano-Textured Silicone Encapsulant. J. Nanosci. Nanotech. 13 (10), 7112-7115. doi:10.1166/ jnn.2013.7889

Lee, Y. S., Kim, K. H., Kim, W. H., Choi, M. H., Jung, C.-H., Choi, J.-H., et al. (2015). Effect of Cross-Linking Density of Silicone Encapsulant on Sulfur
Compound Gas Permeability of Light-Emitting Diode. IEEE Trans. Compon., Packag. Manufact. Technol. 5 (2), 163-167. doi:10.1109/tcpmt.2014.2387195

Lin, Y.-H., You, J. P., Lin, Y.-C., Tran, N. T., and Shi, F. G. (2010). Development of High-Performance Optical Silicone for the Packaging of High-Power LEDs. IEEE Trans. Comp. Packag. Technol. 33 (4), 761-766. doi:10.1109/tcapt.2010. 2046488

Luo, X., Fan, J., Zhang, M., Qian, C., Fan, X., and Zhang, G. (2017). “Degradation Mechanism Analysis for Phosphor/silicone Composites Aged under High Temperature and High Humidity Condition," in 2017 18th International Conference on Electronic Packaging Technology (ICEPT), 1331-1336. doi:10.1109/icept.2017.8046684

Luo, X., Hu, R., Liu, S., and Wang, K. (2016). Heat and Fluid Flow in High-Power LED Packaging and Applications. Prog. Energ. Combustion Sci. 56, 1-32. doi:10. 1016/j.pecs.2016.05.003

Made, R. I., Gao, Y., Syaranamual, G. J., Sasangka, W. A., Zhang, L., Nguyen, X. S., et al. (2017). Characterisation of Defects Generated during Constant Current InGaN-On-Silicon LED Operation. Microelectronics Reliability 76-77, 561-565. doi:10.1016/j.microrel.2017.07.072

Manconi, I., and Lens, P. N. L. (2009). Removal of H2S and Volatile Organic Sulfur Compounds by Silicone Membrane Extraction, (in English). J. Chem. Technol. Biotechnol. 84 (1), 69-77. doi:10.1002/jctb.2008

Nazi, M., Malek, R. M. A., and Kotek, R. (2012). Modification of $\beta$-cyclodextrin with Itaconic Acid and Application of the New Derivative to Cotton Fabrics. Carbohydr. Polym. 88 (3), 950-958. doi:10.1016/j.carbpol.2012.01.047

Pan, Z., Chen, M., Zeng, K., and Kang, Y. (2021). Synthesis of Epoxy-Modified Methyl Phenyl Silicone Resins for LED Encapsulation. Silicon. doi:10.1007/ s12633-020-00868-6

Salehpour, S., and Dube, M. A. (2012). Reaction Monitoring of Glycerol StepGrowth Polymerization Using ATR-FTIR Spectroscopy, (in English). Macromolecular React. Eng. 6 (2-3), 85-92. doi:10.1002/mren.201100071

Singh, P., and Tan, C. M. (2018). Time Evolution of Packaged LED Lamp Degradation in Outdoor Applications, (in English). Opt. Mater. 86, 148-154. doi:10.1016/j.optmat.2018.10.009

Taguchi, T. (2008). Present Status of Energy Saving Technologies and Future prospect in white LED Lighting, (in English). IEEJ Trans. Elec Electron. Eng. 3 (1), 21-26. doi:10.1002/tee.20228

Tan, K.-Z., Lee, S.-K., and Low, H.-C. (2021). LED Lifetime Prediction under Thermal-Electrical Stress. IEEE Trans. Device Mater. Relib. 21 (3), 310-319. doi:10.1109/tdmr.2021.3085579

Tong, L., Feng, Y., Sun, X., Han, Y., Jiao, D., and Tan, X. (2018). High Refractive index Adamantane-Based Silicone Resins for the Encapsulation of LightEmitting Diodes, (in English). Polym. Adv. Technol. 29 (8), 2245-2252. doi:10.1002/pat.4335

Wang, M., Du, Q., Li, Y., Xu, J., Gao, J., and Wang, H. (2019). Effect of Steam on the Transformation of Sulfur during Demineralized Coal Pyrolysis. J. Anal. Appl. Pyrolysis 140, 161-169. doi:10.1016/j.jaap.2019.03.011

Wang, P. C., Lin, C. L., Su, Y. K., and Chien, P. C. (2014). Reliability Testing in GaN-based Blue Light-Emitting Diodes by Doping TiO2 Nanoparticles into Silicone Encapsulation. Jpn. J. Appl. Phys. 53 (6), 06je10. doi:10.7567/jjap.53.06je10

Watzke, S., and Altieri-Weimar, P. (2015). Degradation of Silicone in white LEDs during Device Operation: a Finite Element Approach to Product Reliability Prediction. Microelectronics Reliability 55 (5), 733-737. doi:10.1016/j.microrel. 2015.02.008

Wu, J., Dong, J., Wang, Y., and Gond, B. K. (2017). Thermal Oxidation Ageing Effects on Silicone Rubber Sealing Performance. Polym. Degrad. Stab. 135, 43-53. doi:10.1016/j.polymdegradstab.2016.11.017

Wu, X. T., Li, X., Hao, L., Wen, X., Lan, L., Yuan, X., et al. (2017). "Effect of Vulcanization Temperature and Humidity on the Properties of RTV Silicone Rubber," in Presented at the 4th International Conference on Advanced Composite Materials and Manufacturing Engineering 2017. doi:10.1088/ $1757-899 x / 207 / 1 / 012011$

Zhang, S.-U. (2015). Quantification of Silicone Degradation for LED Packages Using Finite Element Analysis. Microelectronics Reliability 55 (12), 2678-2684. Part B. doi:10.1016/j.microrel.2015.09.006

Zhang, Y., Xu, J., Ding, M., Zhao, D., Huang, H., Lu, G., et al. (2016). Wafer-Level Light Emitting Diode (WL-LED) Chip Simplified Package for Very-High Power Solid-State Lighting (SSL) Source. IEEE Electron. Device Lett. 37 (2), 197-200. doi:10.1109/led.2015.2509462 
Zibold, A., Dammann, M., Schmidt, R., Konstanzer, H., and Kunzer, M. (2017). Influence of Air Pollutants on the Lifetime of LEDs and Analysis of Degradation Effects. Microelectronics Reliability 76-77, 566-570. doi:10.1016/j.microrel. 2017.07.019

Conflict of Interest: The authors declare that the research was conducted in the absence of any commercial or financial relationships that could be construed as a potential conflict of interest.

Publisher's Note: All claims expressed in this article are solely those of the authors and do not necessarily represent those of their affiliated organizations, or those of the publisher, the editors, and the reviewers. Any product that may be evaluated in this article, or claim that may be made by its manufacturer, is not guaranteed or endorsed by the publisher.

Copyright (C) 2022 Chen, Chen, Cao, Cui, Fan, Zhang and Fan. This is an open-access article distributed under the terms of the Creative Commons Attribution License (CC $B Y)$. The use, distribution or reproduction in other forums is permitted, provided the original author(s) and the copyright owner(s) are credited and that the original publication in this journal is cited, in accordance with accepted academic practice. No use, distribution or reproduction is permitted which does not comply with these terms. 